\title{
El Paisaje y el Indio, en la Literatura Peruana
}

NADIE puede negar la importancia espiritual que tiene el medio en 1 el proceso cultural del Perú. La geografía ha divido profundamente el pasado de nuestro país, fomentando esa vida localista, sin lazos de unión, sin nexo espiritual, y por esto un estudio de nuestra literatura nos indica cómo el paisaje y el indio dejan su garra en la emoción artística.

Luis Alberto Sánchez dice que en el Perú se puede hablar de tres regiones con contenido ideológico distinto: el Sur, región de volcanes, con cordilleras bravas, es también el país de las revoluciones y de los hombres viriles como Vigil, Luna Pizarro o Urquieta. E1 Centro es la región del remanso, y de fuga, donde surge el humor como en Ricardo Palma o la crítica constructiva de González Prada. El Norte es sereno y filosófico: en él surge la poesía honda de Va1lejo, o el sentido filosófico de Antenor Orrego y Mariano Ibérico Rodríguez.

Uriel Garcia dice que nuestro paisaje abarca históricamente cuatro regiones distintas: El Antí es el alma elemental, primaria, la fuerza de la selva; el Cunti es la tradición, la Sierra; el Colla es la règión de las llanuras donde el hombre es un conquistador; el Chincha, la región de la costa, propia del alma de inmigrante, que es inestable como el mar.

Pero literariamente se puede hablar de dos regiones opuestas: la costa y la sierra. Hasta hace poco sólo se ha oído la voz de la costa, donde dominó fuertemente la colonia y se ha producido la literatura del perricholismo, según apunta Luis Alberto Sánchez. Como medio urbano, por su cultura y por su progreso, domina económica 
y literariamente, pero los nuevos conceptos mundiales hacen que se vincule a la sierra, y que ésta, como expresión literaria, comience también a surgir como una antítesis a la literatura colonial. La sierra, por su belleza magnifica, millonaria en sugestiones, y por su misterioso pasado, en el que habla la voz de viejas generaciones, por su: problema indígena y por su incorporación a la nacionalidad y por tanto a la literatura, ofrece pues una promesa digna de una gran floración literaria que hará al Perú un país con una cultura propia en la que se refleje esa alma que recién va amaneciendo a la vida espiritual.

La montaña propiamente carece aún de significado literario; es la región del porvenir y cuando el hombre civilizado la conquiste, también dará su contribución a la emoción literaria; lo que se ha escrito hasta ahora no se puede apuntar aún como literatura de esa región, sino más bien como literatura sobre la montaña.

\section{El personaje histórico y su importancia literaria}

Así como hay la dualidad geográfica, existe también en el Perú la dualidad racial y cultural. La cultura indigena que floreció dirigida por el Imperio Incaico, fué repentinamente supeditada con la llegada del invasor español. De modo que nuestra literatura toma en mayor o menor porción ambos elementos y cuando el proceso de unidad sea una realidad, por lo menos en el terreno espiritual, se notará con mayor exactitud el enlace en una sola alma de las dos corrientes. espirituales: indígena y española, matizadas por la influencia del negro y los elementos cosmopolitas que estimulan nuestro ambiente espiritual.

El indio, como cualidades intelectuales, tiene el sentido de profunda nostalgia que viene desde la época incaica, lirismo de ausencia. definitiva; tiene sentido panteísta, amor por las cosas, y como tal florece su literatura de fábulas.

El español del siglo xvi llega lleno de soberbia, "religiosidad carnicera", dinamismo sin límites, pasión sin crítica, actitud individualista. $\mathrm{El}$ negro tiene como elementos espirituales amor a lo misterioso, sentido por lo musical y violento, falta de espíritu crítico. 
Lo aborigen y lo exótico en el proceso cultural del Perí

En el estudio de la literatura peruana tenemos que diferenciar dos modos distintos de expresión intelectual y emocional : la literatura aborigen que se expresa valiéndose del idioma quechua y la literatura que usa como vehículo el español. Dentro de este sistema caben, pues, dos distintos períodos : literatura en quechua y literatura en castellano. siones.

La literatura en quechua comprende a su vez dos grandes diviPrimer periodo. Literatura incaica

La literatura incaica fué indudablemente floreciente y estuvo en relación con el desarrollo alcanzado por la organización política de un Imperio que realizó grandes obras artísticas en su arquitectura, escultura, música, indumentaria, etc., de modo que negar valor literario a esta época es sencillamente infantil.

En el estudio de la literatura incaica apuntaremos, ante todo, las siguientes conclusiones:

I. Hubo una literatura privada íntima, que fué eminentemente lírica, y hubo una literatura oficial esencialmente épica.

II. La literatura incaica oficial fué, como stı política, una obra colectiva, anónima, trabajo de todos los elementos sociales.

III. La literatura incaica tuvo sentido panteísta.

IV. La literatura incaica tuvo por vehículo de expresión el quechua y como medio de retención al Quipucamayoc o narrador oficial, y seguramente también elementos de escritura más o menos primitiva, siendo la más popular y accesible la de los quipus.

V. El testimonio de los cronistas y la supervivencia de algunas obras de la época incaica nos indican que serían más copiosas las fuentes de referencia y el conocimiento de estas obras, de no haber sido destruídas por los elementos oficiales de España.

I. El Imperio incaico tenía un grupo selecto de sabios que conocían toda la ciencia oficial de su época y al mismo tiempo ponían 
su inteligencia al servicio del gobierno, componiendo la historia politica del país, en la cual enaltecían las hazañas de sus dioses; esta obra de los amautas - que eran sabios, filósofos y creadores- era aprendida de memoria, recitada y cantada por los quipucamayoc, en las grandes fiestas religiosas, en los taquis solemnes, en los desfiles militares, en las fiestas agrícolas, etc. Parece que la música y el verso eran elementos indispensables para las faenas religiosas, guerreras y agrarias. Esta literatura oficial era abundante en metáforas y grandilocuente, alegre y triunfal, como para enardecer el sentido de la politica imperialista. Así, en su música, la Huanca tiene el sentido de un llamado a las fuerzas creadoras, como el Jarahua es la música de los ritos sagrados y el Huaino es la exaltación de la alegría.

La literatura intima o privada produjo al poeta o Jarahui. Es una literatura erótica, producto del mitimae, o del trasplantado, que deja su terruño al que está ligado por su sangre y su historia y es llevado a otras regiones recién conquistadas para aglutinar políticamente el Imperio; el mitimae resulta un descontento que expresa este sentimiento mediante la fábula que le sirve de vehículo para la crítica y es un nostálgico que se vale de la canción para recordar y poetizar, surgiendo ese profundo sentimiento de nostalgia.

II. La literatura incaica fué una obra, habíamos dicho, colectiva, como la construcción de palacios y templos, de fortalezas y andenes, de caminos y acueductos; apenas si se conoce un cantar atribuído al Inca Pachacutec como única expresión individualista en medio de este océano de labor en común. Dicho cantar dice así: "Nací como lirio en el jardín, y así fuí criado, y como vivo mi edad, envejecí, y como había de morir, así me sequé y mori”; fuera de este cantar del ya citado Inca, según el cronista Garcilaso Inca de la Vega, también se conocía de él una serie de máximas que eran transmitidas de viva voz, como por ejemplo: "El que procura contar las estrellas no sabiendo aún contar los tantos y nudos de las cuentas, digno es de risa."

Todas las otras obras literarias de la expresada época son obras anónimas.

III. La literatura incaica tuvo sentido panteísta; para Luis E. Valcárcel, "como el Nilo ha creado el Egipto, la cordillera andina ha creado la cultura incaica"; el indio vinculado profundamente con la tierra, tiene por ésta verdadero sentimiento materno. 
IV. Seguramente que la literatura tuvo fuera de los quipus otros elementos que sirvieron de escritura, pues se ha encontrado en distintas regiones del país una serie de pictografías y petrografías Gue van indicando la existencia de una escritura más avanzada que la de los quipus; así, por ejemplo, cerca del Cuzco, en el camino a Abancay, existe la famosa piedra que se llama de Saiviti; en Inca el doctor Riva Agüero descubrió las inscripciones de Huaitará, llenas de dibujos, con llamas, pájaros, serpientes y signos seguramente jeroglíficos. En Yucai y Vilcabamba existen también pictografías.

V. Los cronistas se hallan acordes en indicar que existia en la época incaica una abundante literatura oficial que no se había quedado en la poesía lírica, como creen algunos de los críticos, sino que había llegado hasta el teatro, lo que significa ya una modalidad compleja y elevada, tal como se puede demostrar estudiando la historia del teatro griego que surge en el siglo $\mathrm{v}$, o en la época de oro de la civilización griega. Los cronistas nos hablan de la existencia de cuatro géneros teatrales distintos, a saber: La comedia se llamaba Anai-sanca. La farsa recibía el nombre de Llama-llamas y de Hayachucas. La tragedia se llamaba Hanamsi. Cieza de León nos habla de las fiestas, en las cuales los hombres cantaban en voz alta villancicos y romances, y nos entera también de las representaciones teatrales, de las que textualmente dice: "En mitad de la plaza pública tenían puesto, a lo que dicen, un teatro grande con sus gradas muy adornadas, con paños de plumas llenos de chaquería de oro y mantas grandes, riquísimas de su tan fina lana, sembrados de argentería de oro y pedrería. En lo alto de este trono ponían la figura de su Ticiviracocha, grande y rica... bajo de este trono se tenía la figura del sol..."

Fué la obra de limpieza realizada por los religiosos españoles la que quemó quipus, destruyó instrumentos musicales, incendió templos y quemó todos los objetos litúrgicos, so color de herejía, destruyendo así el testimonio intelectual del incario.

Poco nos ha quedado, y ese poco se refiere a cuentos, poesías y teatros.

El cuento incaico.-Uno de los más notables es el del puma y el zorro, así como la ficción sucedida a un pastor llamado Acoyanapa.

Las fábulas más hermosas son aquellas que se refieren a los gorriones, el puma y el zorro, el zorro y el sapo. 
Las canciones están llenas de un hondo sentido lírico, tal como se puede observar en la siguiente:

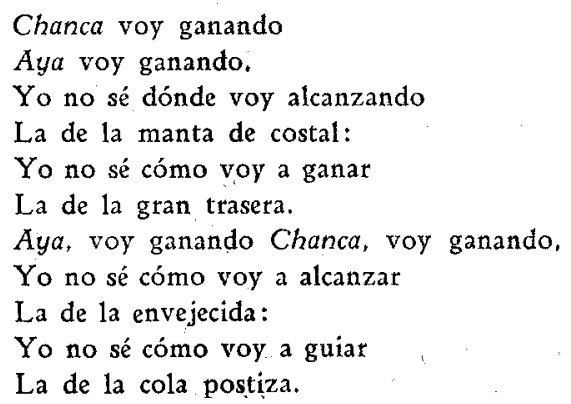

Pero lo más importante que poseemos de la literatura incaica está contenido en el drama Ollantay.

Teatro quechua.-El Ollantay. Mucho se ha discutido sobre la autenticidad incaica de este drama. Nosotros defendemos que es incaico, basándonos en las siguientes razones:

Es un drama incaico porque se han encontrado de él varios códices o copias, como la del cura Valdés, la del cura Justiniani, la copia del Convento de Santo Domingo y la versión oral del indio Fabián Tito, así como la inclusión de su argumento en obras de la época del virreinato, como el poema "Armas antárticas" de Miramontes y Zuazola; todo ello va indicando que estos distintos códices eran tomados de diversas versiones orales, conocidas por destacados elementos de la nobleza indígena.

Es un drama incaico por el idioma que usa, que es un quechua rudo, primitivo y de poca flexibilidad, comparado con el quechua de dramas escritos en plena época colonial o republicana; tal diferencia en el idioma indica diferencia de épocas.

Es drama incaico por su misma falta de trabazón, pues parece que ésta falta en algunos actos que fueron seguramente olvidados por los narradores, o acaso "censurados" por el criterio religioso o político de los hombres de la colonia.

Es drama incaico porque se nutre de elementos históricos, como el rebelde Ollanta que se sublevó en la hoy llamada Fortaleza de Ollantaytambo, y la tradición habla incluso de una inscripción o incapinta, en las afueras de Ollantaytambo, como un testimonio de la derrota de los rebeldes. 
CónIces.-Del Ollantay hay distintos códices o versiones: 1) el códice del cura Valdés, quien hizo representar el drama en 1780 con motivo de la sublevación de Tupac Amaru. 2) El códice del Convento de Santo Domingo. 3) El códice del cura Justiniani. 4) El códice publicado por José Palacios en el periódico Museo Erudito en 1837. 5) E1 códice paseño.

Las opiniones más notables sobre el drama y las versiones más en boga son, ante todo, la del doctor Bernardino Pacheco, traductor de la obra al castellano. También existe la traducción de Barranca, así como la de Pacheco Zegarra, a la que se refiere la crítica publicada en 1890 por Midendorf. A todo esto habría que agregar una restauración de la leyenda de Ollantay que ha servido al escritor Ricardo Rojas para publicar su tragedia, que podemos decir resulta así una nueva versión de la pieza.

Argumento.-E1 drama está dividido en tres actos y los sucesos relatados se realizan en la ciudad de Cuzco y en Ollantaytambo. El personaje principal es Ollantay, bravo capitán que pide al Inca Pachacutec la mano de la princesa Cusi Kcoillor; éste le rechaza porque la ley impide el matrimonio con personas que no pertenezcan a la nobleza. Ollantay, resentido, se despide del Cuzco con esta tremenda imprecación:

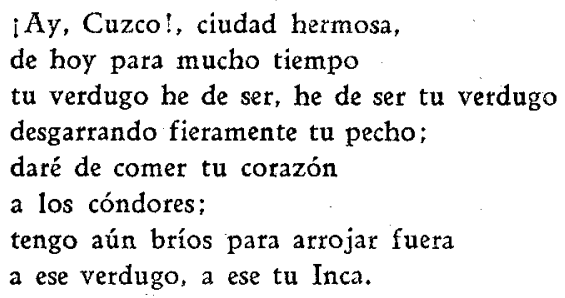

Ollantay parte a la región de los antis y subleva a sus soldados mientras Cusi Kcoillor es encerrada dentro del Claustro de las Acllas, donde llega a tener a su hija que se llama Imasumad, quien llega a sentir profunda impresión por los desgarradores lamentos que lanza su madre prisionera, hasta que se le descubre en una escena ternísima el secreto de su vida. Mientras tanto, Ollantay se ha sublevado y sus tropas han derrotado a las de Ruminahui. Pasa el tiempo y sube al gobierno Tupac Yupanqui; entonces Rumiñahui se desquita de su derrota traidoramente. Ingresa en Ollantaytambo, apresa a los 
rebeldes y se dirige al Cuzco. El Inca por consejo del sumo Sacerdote los perdona, Ollantay se casa con Cusi-Kcoillor y se queda como lugarteniente del Imperio. En la versión de Ricardo Rojas, Cusi-Kcoillor es desterrada y se dirige a la pampa argentina, de donde vuelve el hijo de la tierra y del cielo, en la figura del libertador San Martín.

En cuanto al nombre, hay las siguientes opiniones: 1) De don Vicente Fidel López, para quien la palabra Ollantay viene de HuillaAnta, que significa leyenda de los Andes. 2) Para Fernández Noval viene de Ullu-Anta, que quiere decir el poder del sexo. 3) Para Ricardo Rojas significaría el Titán de los Andes.

El hijo pródigo. Este es un drama de la época colonial escrito en quechua con fines netamente religiosos; una versión de dicha pieza figura en la biblioteca de Cultura Peruana, editada en 1938; el drama se imputa al doctor Juan de Espinoza Medrano. Verdad que en el título de la obra aparece con este nombre: Juan de Espinoza Medrano de los Monteros. Parece que un Medrano de los Monteros, cura de Huamanga, fué también autor de un drama llamado Aprendiz de rico.

El hijo pródigo se ocupa de la vida de un padre de familia que tiene dos hijos, el menor de los cuales se halla ansioso por conocer las inquietudes de la vida y parte, a pesar de las amonestaciones de su padre, llevándose una bolsa bien repleta y un diligente sirviente llamado Uku; el Mundo le sale al encuentro a deslumbrarlo y lo adormece y seduce mediante aquellas mujeres del gozo en beber, comer y jugar, y cuando todo to ha jugado, incluso su vestido, lo despojan de él y lo arrojan y lo desprecian porque ya nọ tiene riquezas; entonces, desesperado, se va como pastor de unos tremendos cerdos, se arrepiente ante la persona de la Palabra de Dios, y vuelve a la casa de su padre donde es recibido amorosamente por éste.

Uska-paukar. Es otro drama de la época colonial, escrito también con fines eminentemente religiosos, y con el fin de enaltecer a la Virgen de Copacabana y recordar su culto.

Entre los personajes más importantes se destacan el príncipe Paukar, su sirviente Kespillo, el demonio o Yuncanina, el anciano Choqqueapu, Koritica, la hija de éste y los cuatro espíritus, o sea los sirvientes del demonio.

El drama tiene 1778 versos y su argumento es el siguiente: 
E1 príncipe Paukar, pobre y triste, deja el Cuzco, su ciudad nativa, donde sus mayores gozaron de esplendor; va acompañado de su sirviente Kespillo y en la noche se guarecen en una cueva donde se le aparece el demonio o Yuncanina, quien le hace firmar con su sangre el derecho de pertenecerle su alma, en cambio de toda clase de beneficios materiales. Rico y poderoso, se dirige a casa de Choqque-Apu, donde es magníficamente alojado; allí se enamora de la bella Koritica; ella lo rechaza, pero la influencia del demonio hace que después lo ame apasionadamente; viven felices, pero llegando el plazo Yuncanina viene para apoderarse del alma de Paukar, mas una procesión de la Virgen dispersa al demonio y sus sirvientes y así el príncipe y la bella Koritica siguen sus amores sin temor al Rey del Infierno.

Otro drama de tema incaico, sumamente interesante, es aquel que se refiere a la ciudad de Piquillacta, donde tuvo lugar el drama de Uksa-maita, quien al igual que Uksa Paukar se enamora de Imasumac, y el padre de ésta decide preferir al que haga llegar primero el agua a dicha región. Esta obra fué terminada por Maita.

Hay otra serie de dramas de tema indígena y de carácter histórico, escritos en nuestros días por el señor Nicanor Jara, por el canónigo Mariano Rodríguez y el cura Zúñiga Cazorla, Alfredo Macedo Arguedas y Andrés Alencastre.

Oraciones.--Se conservan algunas oraciones religiosas de la época incaica, que indican el alto adelanto de sentido. Se dice que "comprendian el significado del Señor indefinido y que la interpretación de la voz Pachacutec es tan amplia que' va más a la del espacio y el tiempo infinitos".

Copiamos la parte de una oración:

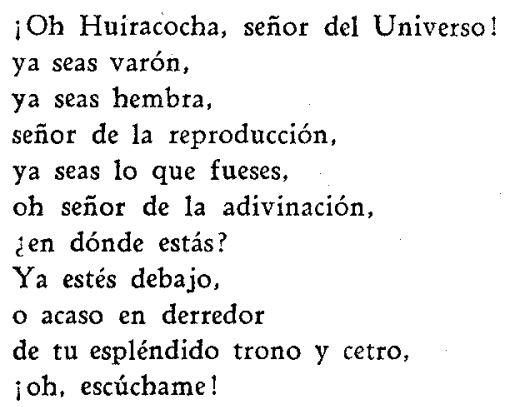




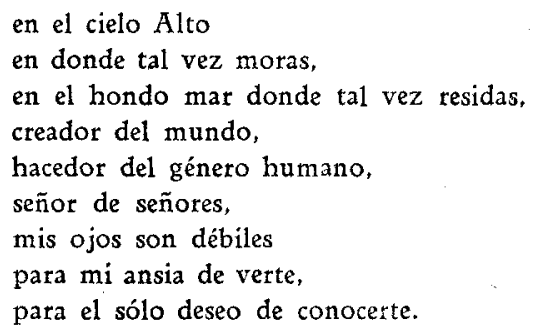

Otras oraciones encierran además un sentido de carácter politico, como la oración a Huiracocha que dice así :

Oh, piadoso creador, tú que ordenas y dispones que exista un señor, el Inca, haz que éste, sus servidores y vasallos permanezcan en paz, que alcancen la victoria sobre sus enemigos $y$ sean siempre vencedores. No abrevies los días del Inca, ni de sus hijos, y dales paz, oh, creador.

\section{Literatura indigena actual. Segundo periodo}

Los indios, a través de 400 años de vida acorralada dentro de las quiebras andinas, desvinculados de la cultura occidental y usando como vehículo de expresión el quecht1a, tienen naturalmente una expresión literaria que es pobre, pero que indica con profunda verdad la dolorosa situación de la raza indígena. Esta literatura se halla basada en el cuento, la fábula y la canción, elementos todos de carácter eminentemente colectivo.

Se han ocupado de tal literatura indígena, entre otras personas: Luis Alberto Sánchez; Julio Delgado, en su libro Folklore y apuntes para la sociología indígena; Hildebrando Castro Pozo, en su libro Nuestra comunidad indígena; José María Arguedas, en Canto Kechua, y finalmente Jorge Basadre, en Literatura Inca.

Cuentos.-El cuento indigena es supersticioso; generalmente se basa en los aparecidos, duendes o almas en pena; dicho género literario cultiva, pues, el argumento de lo extraterrenal, sale de la órbita de lo cotidiano y busca lo irreal ; por este lado abunda en fantasía, pero para mí, es consecuencia de un complejo de inferioridad y de miedo el argumento terrorífico donde el hombre nada vale ante 
las fuerzas sobrehumanas de los personajes en pugna. Otras veces el cuento indígena está lleno de sarcasmo y de burla, pero ello en menor escala; además, algunos cuentos se confunden con las tradiciones incaicas o coloniales.

El cuento del Puma y del Zorro, por ejemplo, indica con mucho humor la enemistad entre ambos, por la cual el grillo, en lucha con los zorros, los deshizo con sus ejércitos, y entonces el zorro le inventó al león una ficticia victoria; éste y sus compañeros fueron atacados por los grillos y quedaron tan mal heridos que desde entonces son tremendos enemigos.

Un cuento relatado en Huancayo a Castro Pozo, habla de cómo un indio Tomás vino a convertirse en sirviente del diablo y lo sirvió, sin saber, en un tremendo horno donde se veía danzar a una serie de personas, hasta que por fin habló una de tales almas y pudo escapar de ese infierno.

Otro cuento indigena bastante conocido es aquel que se refiere a las brujas, o sea el Human-Taccta, y cuenta cómo las mujeres a media noche vuelan por el aire con sólo su cabeza, que se desprende del cuerpo, y después de haber realizado sus maldades vuelve y se acopla a su antiguo cuerpo. Otros cuentos nos hablan de cómo un perro o cualquier otro animal se convierte en persona y después se metamorfosea, a voluntad, nuevamente en perro. $Y$ así podríamos ir enumerando una larga lista de cuentos de indígenas que nos están indicando el sentido de inferioridad en que se colocan, y ponen la fantasía al servicio de lo tenebroso, en manos de lo ultraterreno.

Fábulas.-El indio se ha valido de fábulas para burlarse de sus opresores; generalmente cada fábula encierra una sentencia. Así, por ejemplo, la fábula del Puma y el Zorro tiene la siguiente sentencia: "E1 jactancioso hablador por su boca se condena." La fábula dice que un puma se comió a una gorda llama y enterró el resto. para el día siguiente, pero cuando regresó no encontró nada; resulta que un zorro se había comido el resto; el puma se fué en busca del ladrón y encontró a un zorro dormido, al que quiso despertar para preguntarle, haciéndole cosquillas con un manojo de paja; entonces el zorro, creyendo que eran moscas, dijo: "Afuera, moscas, que acabo de arrebatar su presa al puma."

Otra fábula nos habla de la Huachua y la Zorra y por ella se saca esta sentencia: "Debe uno estar satisfecho con aquello que la 
naturaleza le otorga"; la Zorra le pregunta al ave cómo tienen sus hijos las patitas rojas, $\mathrm{y}$ el ave le contesta que tostándolas sobre brasas.

Canciones.-En la canción triste es donde se interpreta verdaderamente el alma indígena; hay canciones en quechua y otras bilingües en quechua y castellano; acaso este bilingüismo, que nos recuerda la sintaxis de algunos cronistas de la conquista, pueda ser el amanecer de un idioma nuevo. Las canciones rebosan, como dice Luis Alberto Sánchez, de nostalgia, ironía y ternura. Van como ejemplo estas dos canciones:

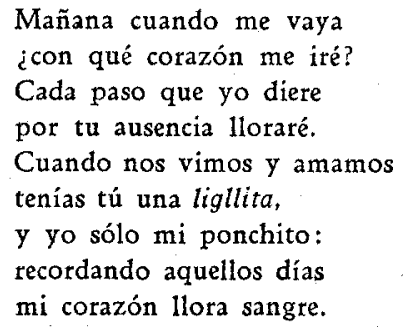

Arguedas traduce composiciones como ésta:

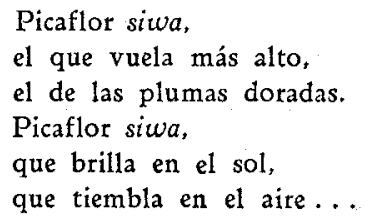

La poesía del indígena se halla íntimamente vinculada con el medio natural en que éste vive, y a su hora, cuando se culturice, tal literatura alcanzará mayores contornos.

LITERATURA INDÍGENA INDIVIDUAL.-En medio de esta literatura anónima, obra colectiva de los campesinos peruanos, aparecen ciertos testimonios que indican las posibilidades de una futura literatura indígena. Me refiero a un poeta y un dramaturgo.

El poeta se llama Eustaquio R. Aweranka, nacido en Puno; colaboró en Boletín Titicaca y escribió en 1939 unos versos con motivo de la muerte de Mariátegui : 
Nuestro joven José Mariátegui

para siempre, para siempre se ha perdido;

dentro de su corazón de oro

se ha llevado nuestro cariño.

En la Laguna del Inca

el Sol nuestro padre está llorando;

nuestra madre Luna,

llora junto con él.

E1 amauta con los colonos

para siempre, para siempre

se ha perdido;

en su triste desconsuelo

las palomas llotan

y los jóvenes junto con ellas también.

Los originales están escritos en quechua.

El poeta dramático se llama Inocencio Mamani y también es oriundo de Puno; su obra ha sido comentada en la Revista Amauta, por la pluma del escritor cuzqueño doctor José Gabriel Cosío y también por Gabriel Collazos.

Gabriel Collazos dice que hay en esta obra "cuadros enmarcados en una peculiaridad y colorido emocionales". La tendencia de la obra es aleccionar al indio, demostrando las perjudiciales consecuencias de la coca y del alcohol.

El doctor José Gabriel Cosío, en un artículo publicado en la misma revista opina: "Tucuypa munascaan es, en verdad, un drama muy sencillo. Lo que en él valen son los diálogos, los apotegmas y las consejas. El estilo, en fin. Para interesar escénicamente le faltarían más movimiento, más vida, más personajes. Parece más bien un romance pastoril y no una obra teatral." El argumento se refiere a una india guapa que se ha casado con un indio calavera. Ella se llama Pitita y él Melchor. Este es aficionado a cortejar y se va al pueblo como manadero o comprador de ganado. Pitita lo espera temerosa, y con el tiempo la enamora un tal Silico, pero ella está decidida a no engañar a su marido. En el segundo acto llega Melchor, que había sido apaleado y amarrado consiguiendo finalmente fugarse. E1 drama tiene tendencia evidentemente moral, ataca los efectos del alcohol y de la coca y los perjuicios que causa en las personas que abusan de tales tóxicos.

Esta es a grandes rasgos la literatura indigena, que naturalmente se halla íntimamente vinculada con la literatura mestiza hecha 
por mestizos, como en los casos de Julio Ruviros y de Kilko Waraca, que interpretan en sus dramas escenas de vivo sentido campesino e indio donde saben interpretar el alma de los hombres del Ande.

Alfredo Yépez Miranda, Cuzco, Perú. 